\title{
Impact of HIV risk factors on survival in Iranian HIV-infected patients: A Bayesian approach to retrospective cohort
}

\author{
Mohammad Reza Maracy ${ }^{1}$, Shayan Mostafaei², Mohsen Moghoofei ${ }^{3}$, Marjan Mansourian $^{1}$ \\ ${ }^{1}$ Department of Epidemiology and Biostatistics, School of Health, Isfahan University of Medical Science, Isfahan, Iran \\ ${ }^{2}$ Department of Biostatistics, Faculty of Medical Sciences, Tarbiat Modares University, Tehran, Iran \\ ${ }^{3}$ Department of Virology, Faculty of Medicine, Iran University of Medical Science, Tehran, Iran
}

\begin{abstract}
Introduction: Human immunodeficiency virus (HIV) infection is recognized as a human health issue, and its social, cultural, economic, and political consequences lead to an extremely large problem for human health. The aim of this study is to evaluate association between risk factors and HIV-positive patient's survival time.

Material and methods: In this population-based retrospective cohort study, a total of 245 positive HIV/ AIDS infected patients were included. The required information were collected by an interview and blood testing. The interview was conducted by an expert and trained social worker, using a structured questionnaire. The demographic and risk factors of HIV infection factors such as: age, gender, job status, marital status, education attainment, prison status, injection drug user, heterosexual, homosexual, infected mothers, sexually transmitted disease, sex worker status, addiction, disease stage at diagnosis, CD4+ T-cell count, HBV, HCV, and AIDS were collected. The survival time of HIV patients was considered as a main outcome. Since there was a lot of censored data, we applied Gaussian Mixture Model.

Results: The analysis was done based on data of 205 (84\%) patients. One hundred and sixty (78\%) patients were male and the mean (SD) age of patients was 37.1 (9.3) years, varied from 4 to 65 years. During the study, 43 (21\%) deaths were recorded. Median and mean with their 95\% confidence intervals for survival time were 50.4 (range, 36.6-64.2) and 44.1 (range, 34.4-53.6) months, respectively, based on posterior distribution. Survival time was significantly correlated with the variables of disease stage at diagnosis time, sexually transmitted disease, CD4+ T-cell count, HBV, and AIDS. According to the sign of regression coefficients, there was strong negative correlation between survival time and disease stage at diagnosis time, sexually transmitted disease, HBV, and AIDS. Furthermore, positive correlation was found between survival times with CD4 level.

Conclusions: Since there are numerous national surveys running in Iran to fill in the information gaps on HIV prevalence and related risky behaviors among most at risk population, it is recommended to implement several integrated bio-behavioral surveillance surveys for hidden and hardto-reach populations.
\end{abstract}

HIV AIDS Rev 2017; 16, 2: 100-106 DOI: https://doi.org/10.5114/hivar.2017.68117

Key words: HIV, AIDS, survival time, risk factors, Bayesian.

Address for correspondence: Marjan Mansourian, Department of Epidemiology and Biostatistics, Isfahan University of Medical Science, Hezar Jerib Street, 8169658514 Isfahan, Iran, phone: +98 313792 3256, e-mail: j_mansourian@hlth.mui.ac.ir
Article history:

Received: 17.06.2016

Received in revised form: 9.01.2017

Accepted: 9.02.2017

Available online: 31.05 .2017
International Journal of HIV-Related Problems

HIV \& AIDS

R e vi e w 


\section{Introduction}

Human immunodeficiency virus (HIV) infection is recognized as a human health problem in all around the world. Its social, cultural, economic, and political consequences lead to an extremely large problem for human health [1]. $\mathrm{HIV}$ is a major global public health issue and according to WHO report it is estimated to claim more than 36.7 million lives so far. In 2014, 1.2 (1.0-1.5) million people have died from HIV-related causes across the world. There were approximately 36.9 (34.3-41.4) million people that were living with HIV at the end of 2014 with 2 (1.9-2.2) million of new HIV cases in 2013 globally [2]. HIV is on the downward trend globally as new HIV infections have fallen by $38 \%$; new HIV infections among children have decreased by $58 \%$ since 2001, and number of deaths from AIDS-related diseases have declined by 35\%, since the peak in 2005 to 2013 [3]. Since 2001 to 2009 , HIV was still on the upward trend in adults and children as well as newly HIV infected cases in some regions, especially in the Middle East and North Africa [4], and it continues to challenge human communities with its health, social, economic, cultural, and political consequences. Based on statistical report of World Health Organization (WHO), the prevalence rate of HIV/AIDS in Iran has increased from low to concentrated level of epidemic [5]. The prevalence in overall population is below $1 \%$; this rate, however, has surpassed $5 \%$ in some high-risk groups such as IDUs $[6,7]$. For effective management and planning on the prevention and control of HIV, it is crucial to focus on people living with HIV and to identify prime high-risk groups, as well as concentrating on the HIV/AIDS epidemic in the country and its longitudinal patterns of changes [8-10]. There are three major groups of risk factors that have been reported to increase mortality among the HIV-infected patients on highly active antiretroviral therapy (HAART) including HIV-related risk factors (AIDS defining diseases and insufficient response to HAART), co-morbidities such as hepatitis $\mathrm{C}$, and non-HAART-related lifestyle factors such as drug, smoking, and alcohol abuse [11-13]. Several factors have been related to risk of HIV infection, varying from individual demographic characteristics for instance gender, age, and marital status, socio-economic status such as education, wealth, sexual behavior (hetero-/homosexual), clinical characteristics (i.e. tuberculosis [TB], CD4+ T-cell count, $\mathrm{HBV}, \mathrm{HCV}, \mathrm{AIDS})$, and addiction risk factors. In general, HIV prevalence tends to peak at a younger age for women (i.e. between the ages of 30 and 34) than for men (in late 30s and early 40s). Besides gender and age, another demographic factor that has been noted to show a particularly strong association with the risk of HIV infection is marital status [14]. Patients with HIV are also likely to be at risk for other infectious pathogens. Co-infection with HIV and HBV and/ or HCV is common, because all of these diseases spread by similar routes of viral transmission. On the other hand, viral hepatitis complicates the clinical course and management, and may also adversely affect HIV treatment [15]. Considering the variety of risk factors affected the survival of HIV, this study aimed to assess association between risk factors and HIV patient's survival time.

\section{Material and methods}

\section{Setting}

In this population-based retrospective cohort study, we collected HIV/AIDS surveillance data from the Counseling Center of Behavioral Diseases in Isfahan central of Iran during 2001-2014. Only positive HIV/AIDS infected patients (those who were positive by enzyme-linked immunosorbent assay [ELISA] method and confirmed by Western blot method) had attended the Counseling Center of Behavioral Diseases and were included in the study. Based on the data protection policy, all names were removed and replaced by a code derived from the date of the HIV diagnosis of the patients. The study included 245 HIV-infected patients.

Information were collected by an interview and blood testing. The interview was conducted by an expert and trained social worker, using a structured questionnaire. It comprised of demographic data and risk factors for HIV infection. The demographic and risk factors of HIV infection include age, gender, job status, marital status, education attainment, prison status, injection drug user (IDU), heterosexual, homosexual, infected mothers, sexually transmitted disease (STD), sex worker status, addiction, disease stage at diagnosis, CD4+ T-cell count, HBV, HCV, and AIDS. In order to detect HBV, HCV and HIV, $5 \mathrm{ml}$ blood sample was taken from each individual and sent to the Infectious Diseases and Tropical Medicine Research Center of Isfahan. Samples were tested for HBV, HCV, and HIV using the ELISA method (Diapro, Italy) with more than $90 \%$ sensitivity.

A third-generation ELISA (Diapro, Italy) was used to determine anti-HCV. Patients with ELISA and western blot positive (for HIV) and ELISA positive (for $\mathrm{HCV}$ ) were considered as HIV and HCV co-infection. CD4+ cell counts were measured by flow cytometry (Partec, Germany).

\section{Statistical analysis}

All data were summarized and demonstrated as frequency (\%) for categorical variables or mean \pm standard deviation (SD) for continuous variables. The survival time of HIV patients was considered as main outcome. Since there was a lot of censored data, we applied Gaussian Mixture Model (GMM). This model is commonly used as a parametric model of the probability distribution of continuous measurements or features in a biometric system. It is also important to note that because the Gaussian components are acting together to model the overall feature density, these models can provide tools for traditional fitting of limited mixtures of univariate and multivariate normal distributions $[16,17]$.

In this model fitting, the survival time was assumed as dependent variables, while the demographic and risk factors of HIV infection as independent variables. We applied a hie- 
Table 1. Descriptive statistics for general characteristics of study subjects; mean \pm SD for continues variables and number (\%) for the categorical variables

\begin{tabular}{|c|c|}
\hline Characteristics & Descriptive statistics \\
\hline Age (years) & $37.1 \pm 9.3$ \\
\hline$<16$ & $4(2)$ \\
\hline $16-29$ & $28(13.7)$ \\
\hline $30-39$ & $100(48.8)$ \\
\hline $40-49$ & $53(25.9)$ \\
\hline$>49$ & $20(9.8)$ \\
\hline Survival time (months) & $44.1 \pm 32.1$ \\
\hline \multicolumn{2}{|l|}{ Gender } \\
\hline Male & $160(78)$ \\
\hline Female & $45(22)$ \\
\hline \multicolumn{2}{|l|}{ Educational level } \\
\hline No educated & $10(5)$ \\
\hline College & $182(91)$ \\
\hline University & $8(4)$ \\
\hline \multicolumn{2}{|l|}{ Job status } \\
\hline Unemployed & $77(37.6)$ \\
\hline Employed & $125(62.4)$ \\
\hline \multicolumn{2}{|l|}{ Marital status } \\
\hline Married & 89 (43.4) \\
\hline Single & $83(40.5)$ \\
\hline Divorce or Widow/er & $32(16.1)$ \\
\hline \multicolumn{2}{|l|}{ Disease stage* } \\
\hline Mild & $112(56)$ \\
\hline Moderate & $24(12)$ \\
\hline Severe & $36(18)$ \\
\hline Very severe & $28(14)$ \\
\hline \multicolumn{2}{|l|}{ Prison status } \\
\hline No & $66(34.9)$ \\
\hline Yes & $123(65.1)$ \\
\hline \multicolumn{2}{|l|}{ Injecting drug use (IDU) } \\
\hline No & $78(38)$ \\
\hline Yes & $127(62)$ \\
\hline \multicolumn{2}{|l|}{ Heterosexual } \\
\hline No & $113(65.5)$ \\
\hline Yes & $87(43.5)$ \\
\hline \multicolumn{2}{|l|}{ Homosexual } \\
\hline No & $194(97)$ \\
\hline Yes & $6(3)$ \\
\hline \multicolumn{2}{|l|}{ Infected mothers } \\
\hline No & $177(88.5)$ \\
\hline Yes & $23(11.5)$ \\
\hline
\end{tabular}

Table 1. Cont.

\begin{tabular}{|c|c|}
\hline Characteristics & Descriptive statistics \\
\hline \multicolumn{2}{|c|}{ Sexually transmitted disease(STD) } \\
\hline No & $194(97)$ \\
\hline Yes & $6(3)$ \\
\hline \multicolumn{2}{|c|}{ Tuberculosis disease } \\
\hline Negative & $190(92.7)$ \\
\hline Positive & $15(7.3)$ \\
\hline \multicolumn{2}{|l|}{ Sex worker } \\
\hline No & $74(39.2)$ \\
\hline Yes & $115(60.8)$ \\
\hline \multicolumn{2}{|l|}{ Addiction } \\
\hline Negative & $52(27.5)$ \\
\hline Positive & $136(72.5)$ \\
\hline \multicolumn{2}{|l|}{ CD4 categorize } \\
\hline$<200$ & $56(30.6)$ \\
\hline $200-499$ & $82(44.8)$ \\
\hline$>500$ & $45(24.6)$ \\
\hline \multicolumn{2}{|l|}{ HBV } \\
\hline Negative & $194(95.6)$ \\
\hline Positive & $9(4.4)$ \\
\hline \multicolumn{2}{|l|}{$\mathrm{HCV}$} \\
\hline Negative & $106(52.2)$ \\
\hline Positive & $97(47.8)$ \\
\hline \multicolumn{2}{|l|}{ AIDS } \\
\hline Negative & $140(70.4)$ \\
\hline Positive & $59(29.6)$ \\
\hline
\end{tabular}

*Difference between disease stage at diagnosis and presentation times

rarchical Bayesian approach to report the Bayes estimates, and make inferences of model parameter. Markov chain Monte Carlo (MCMC) algorithms, such as the Gibbs sampling, was used to find Bayes estimates and their corresponding 95\% confidence intervals (CIs). Data were analyzed using Statistical Package for Social Sciences version 18.0 (SPSS, Inc., Chicago, IL, USA) and OpenBugs 3.2.2, free software for the Bayesian analysis of complex statistical models using Gibbs sampling approach [18].

\section{Results}

A total of $245 \mathrm{HIV}$-infected patients participated in the study. Forty (16\%) patients were excluded because of incomplete information. The analysis was done based on the data of 205 (84\%) patients. One hundred and sixty (78\%) patients were male and the mean (SD) age of patients was 37.1 (9.3\%) years, varied from 4 to 65 years. During the study, 43 (21\%) deaths were recorded. Risk of death was 94.5\% in patients registered with two or more risk factors. Ninety-one percent of the participants have college educa- 
Table 2. Results of HIV patients' characteristics on survival time based on 10-year follow-up using Finite Gaussian Mixture Model with Bayesian approach in Isfahan, Iran

\begin{tabular}{|c|c|c|c|}
\hline Characteristics & Mean $(\beta)$ & SD & Bayesian $95 \% \mathrm{Cl}$ \\
\hline Disease stage $^{\star}$ & -4.52 & 1.03 & {$[-6.53 ;-2.51]$} \\
\hline \multicolumn{4}{|l|}{ Prison status } \\
\hline Negative & Reference & & \\
\hline Positive & -3.93 & 3.34 & {$[-10.5 ; 2.62]$} \\
\hline \multicolumn{4}{|c|}{ Injecting drug use (IDU) } \\
\hline Negative & Reference & & \\
\hline Positive & -3.83 & 2.93 & {$[-5.91 ; 9.58]$} \\
\hline \multicolumn{4}{|l|}{ Heterosexual } \\
\hline Negative & Reference & & \\
\hline Positive & -1.12 & 1.76 & {$[-4.58 ; 2.34]$} \\
\hline \multicolumn{4}{|l|}{ Homosexual } \\
\hline Negative & Reference & & \\
\hline Positive & -1.67 & 3.99 & {$[-9.49 ; 6.16]$} \\
\hline \multicolumn{4}{|c|}{ Infected mothers } \\
\hline Negative & Reference & & \\
\hline Positive & -1.01 & 3.34 & {$[-7.55 ; 5.54]$} \\
\hline \multicolumn{4}{|c|}{ Sexually transmitted disease (STD) } \\
\hline Negative & Reference & & \\
\hline Positive & -7.48 & 3.53 & {$[-14.4 ;-0.57]$} \\
\hline \multicolumn{4}{|c|}{ Tuberculosis disease } \\
\hline Negative & Reference & & \\
\hline Positive & -1.89 & 2.08 & {$[-5.97 ; 2.19]$} \\
\hline \multicolumn{4}{|l|}{ Sex worker } \\
\hline Negative & Reference & & \\
\hline Positive & -1.19 & 3.25 & {$[-7.56 ; 5.18]$} \\
\hline \multicolumn{4}{|l|}{ Addiction } \\
\hline Negative & Reference & & \\
\hline Positive & -1.29 & 2.17 & {$[-5.54 ; 2.96]$} \\
\hline \multicolumn{4}{|l|}{ CD4 } \\
\hline$<200$ & Reference & & \\
\hline $200-499$ & 2.56 & 1.12 & {$[0.35 ; 4.76]$} \\
\hline$>500$ & 3.71 & 1.19 & {$[1.38 ; 6.03]$} \\
\hline \multicolumn{4}{|l|}{ HBV } \\
\hline Negative & Reference & & \\
\hline Positive & -3.97 & 1.45 & {$[-6.82 ;-1.13]$} \\
\hline \multicolumn{4}{|l|}{$\mathrm{HCV}$} \\
\hline Negative & Reference & & \\
\hline Positive & -0.61 & 2.91 & {$[-6.32 ; 5.10]$} \\
\hline \multicolumn{4}{|l|}{ AIDS } \\
\hline Negative & Reference & & \\
\hline Positive & -5.51 & 2.33 & {$[-10.1 ;-0.95]$} \\
\hline
\end{tabular}

*Difference between disease stage at diagnosis and presentation times; significant results are bold based on the $95 \%$ Bayesian confidence interval; estimated Bayesian approach controlling for age, gender, job status, education level, and marital status 
tion and most of them were married (43.4\%). Median and mean with their $95 \%$ confidence intervals (CIs) for survival time were 50.4 (36.6-64.2) and 44.1 (34.4-53.6) months, respectively, based on posterior distribution. $65.1 \%$ of participants were prisoner, but there is no correlation between living in prison with none of the behavioral risks $(p>0.05)$. The proportion of injecting drug use between participants was $62 \%$. Most of the participants were sex workers (60.8\%). The percent of participants with HBV, HCV, and tuberculosis infected was $4.4 \%, 47.8 \%$, and $7.3 \%$, respectively. Furthermore, $29.6 \%$ of the participants were AIDS-positive. The life expectancy in patients at the age of 20 was 36 years; it was less than the life expectancy of the general Isfahan population. At the end of study, about $79 \%$ of patient's survival times were right censored. Other characteristics are shown in Table 1.

Estimates of parameters based on posterior functions were obtained using the Open BUGS software versions 3.2.2. For the underlying model, 10,000 iterations were discarded as burn-in sample to eliminate the impact of starting values, and then 100,000 iterations with tuning of 50 followed to obtain Bayes estimates (posterior means and SDs) of parameters and related 95\% Bayesian intervals. Convergence was assessed by visual assessment of the Markov chain for all parameters. Trace plots of samples and Monte Carlo errors were checked (results not shown).

Based on 95\% high posterior density (HPD) from ratios of the Monte Carlo errors relative to the respective SDs of the estimates, survival time was significantly associated with the variables of disease stage at diagnosis time $(p<0.001)$, sexually transmitted disease $(p=0.035)$, CD4+ T-cell count $(p<0.01), \operatorname{HBV}(p=0.01)$, and AIDS $(p=0.02)$. According to the sign of regression coefficients, there was strong negative correlation between survival time and disease stage at diagnosis time, STD, HBV, and AIDS. Furthermore, positive correlation was found between survival times with CD4 level. Survival time of HIV-infected participants has negative correlation with the other variables of the study, but none of them was not statistically significant (Table 2).

\section{Discussion}

In the current study, to assess risk factors on patient's survival time considering as a difference between disease stage at diagnosis and patient's death, we applied a Finite Gaussian Mixture Model with Bayesian approach. It accounts for many censored values and an inadequate sample size. Findings of the present study showed a strong relationship between disease stage, sexually transmitted disease (STD), CD4+ T-cell count, HBV coinfection, and AIDS with the survival time of HIV patients. In developed countries, several factors were reported including tuberculosis and HBV coinfection, intravenous drug abuse, CD4+ cell count lower than 500 cells $/ \mathrm{mm}^{3}$, and black or brown skin as predictors for AIDS progression [19]. Based on data from the routine reporting system in Iran, up to the middle of 2009, 20,130 HIV-positive cases were detected. This proportion is much higher in devel- oped countries. It seems that the lower detection case rate is one of the problems in some Middle East and North Africa (MENA) countries including Iran [20]. Of these, 24\% to $27 \%$ have undiagnosed disease and are unaware of their HIV infection. In addition, data from the Health Ministry of Iran has indicated that on average, HIV-infected people developed AIDS within five years. It could be concluded that HIV-positive cases are detected after a long delay. Therefore, the lack of reporting of HIV-positive detection rates and long delays are two main threats for spreading of HIV among the population that it could reduce the survival time [21]. Some studies showed that CD4+ T-cell count, viral load, and IDU were predictors of survival time. These studies were consistent with our finding, in which CD4+ T-cell count less than 200 was significant effect on survival, but in-contrast with our result, IDU was not independent statistically significant predictor of mortality [22-24]. Based on the study conducted by Larsen et al., the risk of HIV-related death was not increased in IDUs compared to non-IDUs. The result of this study was in agreement with finding of current work [12]. Another study conducted by Cohen et al. showed that CD4+ T-cell count, history of transactional sex, and HCV coinfection predicted mortality in women's HIV interagency with 1 year on highly active anti-retroviral therapy [25]. In another investigation, Rezaianzadeh et al. demonstrated that HCV coinfection increased mortality rate in HIV-infected patients, rather than HCV-uninfected patients in HIV patients [26]. The results of these study were compatible with our finding about CD4+ T-cell count, except the history of transactional sex or HCV. According to study performed by Grzeszczuk et al., no association was found between HCV seropositive and survival, and this result was in agreement with our findings [27]. Based on conducted studies in HIV patients, low CD4+ T-cell count at the time of tuberculosis treatment initiation was associated with early mortality and increased risk of death [28-31]. Also another study showed that history of tuberculosis and not using antiretroviral drugs was significantly associated with higher mortality in HIV patients [32]. Komati et al. studied HIV-infected patients who started antiretroviral therapy at low CD4+ T-cell count, and tuberculosis at baseline was a death predictor. Tuberculosis during follow-up was an independent predictor of death even after adjustments for baseline risk factors, including CD4+ T-cell count and viral load. These are contrast results comparing to our findings [33]. Two other independent studies showed that risk factors for death were clinical AIDS at baseline, lower baseline CD4+ T-cell count. These results were compatible with findings in our study [34, 35]. Farzadegan et al. investigated the relationship between various methods of measuring viral load and sex, and their combined impact on disease progression. They indicated that men had a higher median viral load than women. Their results remained within the previous 6 months and also after adjustment for drug use, CD4+ T-cell count, and race [36]. Brugal et al. demonstrated that in a cohort of heroin users, approximately one-third of deaths were AIDS-related, onethird were overdose-related, and one-third were due to oth- 
er causes [37]. In contrast, based on our study, there is not significant relationship between heroin addiction and HIV patient's survival time. In a study on HIV patients performed by Nakagawa et al., the greatest risk of excess mortality is due to delays in HIV diagnosis [38]. Another study conducted by May et al. in the UK showed that earlier diagnosis might increase life expectancy [39]. The results of these studies were consistent with our finding. According to report of antiretroviral therapy cohort collaboration study group, a substantial proportion of men infected through sex with men and individuals infected through heterosexual contacts mortality rate was significantly increased compared with the general population [40]. These results are inconsistent with our finding. It should be mentioned that in Iranian community, people try to hide behaviors such as sexual activity. Harm reduction programs among most at risk populations in 2001, which included IDUs, prisoners, and more recently, sex workers are started in Iran. Based on these programs, there is a close cooperation between the Ministry of Health and medical education, prison health department, judicial authorities, and other interested parties, with regards to drug treatment and HIV/AIDS. The governmental support for the implementation of evidence-based harm-reduction policies has increased [41]. Dispute of unsafe sexual activity were not statistically significant effect on survival time in this study, however, sex workers are one of the sources in the transmission of HIV virus to general population. Unfortunately, there are no precise estimates of the percentage of men, especially married men, who are clients of female sex workers (FSWs). Since a large number of FSWs and men sex with men are mobile and remain hidden, implementing serious harm reduction programs will be very important. Improvement can be made, if the current Harm Reduction Programs for certain high-risk groups such as FSWs and IDUs are purposefully implemented [21].

As the country of Iran is realizing some national surveys to get more information on HIV prevalence and related risky behaviors among population at risk, it is recommended to implement several integrated bio-behavioral surveillance surveys for hidden and hard-to-reach populations.

\section{Acknowledgments}

We would like to thank the head and the staff of Centre of HIV in the Departments of Infectious Diseases at Health Center in Isfahan University of Medical Sciences for their support.

\section{Conflict of interests}

The authors declared no potential conflicts of interest with respect to the research, authorship, and/or publication of this article.

\section{References}

1. Kaushik S, Levy JA. HIV/AIDS. In: Desk encyclopedia of microbiology. $2^{\text {nd }}$ ed. Schaechter M (ed.). Academic Press, Oxford 2010; pp. 640-663.
2. World Health Organization. HIV/AIDS 2015. Available at: http:// www.who.int/mediacentre/factsheets/fs360/en/

3. World Health Organization. UNAIDS 2014. Available at: http://www. who.int/mediacentre/factsheets/fs360/en/

4. World Health Organization. UNAIDS report on the global AIDS epidemic 2010. Available at: http://www.unaids.org/globalreport/ documents/20101123_GlobalReport_full_en.pdf

5. Iranian Ministry of Health and Medical Education. Iran Country report on monitoring of the United Nations general assembly special session on HIV and AIDS. Iranian Ministry of Health, Tehran 2008.

6. Mojtahedzadeh V, Razani N, Malekinejad M, et al. Injection drug use in rural Iran: Integrating HIV prevention into Iran's rural primary health care system. AIDS Behav 2008; 12: 7-12.

7. World Health Organization, UNAIDS, UNICEF. Epidemiological fact sheets on HIV/AIDS and sexually transmitted diseases of Islamic Republic of Iran 2004. Available at: http://data.unaids.org/ publications/Fact-Sheets01/iran_en.pdf

8. Montazeri A. AIDS knowledge and attitudes in Iran: results from a population-based survey in Tehran. Patient Education and Counseling 2005; 57: 199-203.

9. Pisani E, Garnett GP, Grassly NC, et al. Back to basics in HIV prevention: focus on exposure. Br Med J 2003; 326: 1384-1387.

10. Khalili H, Soudbakhsh A, Hajiabdolbaghi M, et al. Nutritional status and serum zinc and selenium levels in Iranian HIV infected individuals. BMC Infect Dis 2008; 8: 165.

11. Obel N, Omland LH, Kronborg G, et al. Impact of non-HIV and HIV risk factors on survival in HIV-infected patients on HAART: a population-based nationwide cohort study. PLoS One 2011; 6: e22698.

12. Larsen MV, Omland LH, Gerstoft J, et al. Impact of injecting drug use on response to highly active antiretroviral treatment in HIV-1-infected patients: a nationwide population-based cohort study. Scand J Infect Dis 2010; 42: 917-923.

13. Group DADS. Use of nucleoside reverse transcriptase inhibitors and risk of myocardial infarction in HIV-infected patients enrolled in the D: A: D study: a multi-cohort collaboration. Lancet 2008; 371 : 1417-1426.

14. Magadi M, Desta M. A multilevel analysis of the determinants and cross-national variations of HIV seropositivity in sub-Saharan Africa: evidence from the DHS. Health Place 2011; 17: 1067-1083.

15. Ataei B, Tayeri K, Kassaian N, et al. Hepatitis B and C among patients infected with human immunodeficiency virus in Isfahan, Iran: seroprevalence and associated factors. Hepat Mon 2010; 10: 188-192.

16. Benaglia T, Chauveau D, Hunter DR, et al. Mixtools: An R package for analyzing finite mixture models. Journal of Statistical Software 2009; 32: 1-29.

17. Reynolds D. Gaussian mixture models. Encyclopedia of Biometrics 2009; 659-663.

18. Lunn DJ, Thomas A, Best N, et al. WinBUGS-a Bayesian modelling framework: concepts, structure, and extensibility. Statistics and Computing 2000; 10: 325-337.

19. Chen L, Yang J, Zhang R, et al. Rates and risk factors associated with the progression of HIV to AIDS among HIV patients from Zhejiang, China between 2008 and 2012. AIDS Res Ther 2015; 12: 32.

20. Pierre-Louis AM, Akala FA, Karam HS. Public Health in the Middle East and North Africa: Meeting the Challenges of the Twentyfirst Century. World Bank Publications 2004.

21. DeJong J, Jawad R, Mortagy I, et al. The sexual and reproductive health of young people in the Arab countries and Iran. Reproductive Health Matters 2005; 13: 49-59.

22. Guaraldi G, Brothers TD, Zona S, et al. A frailty index predicts survival and incident multimorbidity independent of markers of HIV disease severity. AIDS 2015; 29: 1633-1641.

23. Lemly DC, Shepherd BE, Hulgan T, et al. Race and sex differences in antiretroviral therapy use and mortality among HIV-infected persons in care. J Infect Dis 2009; 199: 991-998. 
24. Poundstone KE, Chaisson RE, Moore RD. Differences in HIV disease progression by injection drug use and by sex in the era of highly active antiretroviral therapy. AIDS 2001; 15: 1115-1123.

25. Cohen MH, Hotton AL, Hershow RC, et al. Gender-related risk factors improve mortality predictive ability of VACS Index among HIVinfected women. J Acquir Immune Defic Syndr 2015; 70: 538-544.

26. Rezaianzadeh A, Hasanzadeh J, Alipour A, et al. Impact of hepatitis $\mathrm{C}$ on survival of HIV-infected individuals in Shiraz; South of Iran. Hepat Mon 2012; 12: 106.

27. Grzeszczuk A, Wandalowicz AD, Jaroszewicz J, et al. Prevalence and Risk Factors of HCV/HIV Co-Infection and HCV Genotype Distribution in North-Eastern Poland. Hepat Mon 2015; 15: e27740.

28. Lai YJ, Liu EY, Wang LM, et al. Human Immunodeficiency Virus Infection-Associated Mortality during Pulmonary Tuberculosis Treatment in Six Provinces of China. Biomedical and Environmental Sciences 2015; 28: 421-428.

29. Akinyemi JO, Adesina OA, Kuti MO, et al. Temporal distribution of baseline characteristics and association with early mortality among HIV-positive patients at University College Hospital, Ibadan, Nigeria. Afr J AIDS Res 2015; 14: 201-207.

30. Mirani G, Williams PL, Chernoff M, et al. Changing Trends in Complications and Mortality Rates Among US Youth and Young Adults With HIV Infection in the Era of Combination Antiretroviral Therapy. Clin Infect Dis 2015; 61: 1850-1861.

31. Argemi X, Dara S, You S, et al. Impact of malnutrition and social determinants on survival of HIV-infected adults starting antiretroviral therapy in resource-limited settings. AIDS 2012; 26: 1161-1166.

32. Badie BM, Nabaei G, Rasoolinejad M, et al. Early loss to follow-up and mortality of HIV-infected patients diagnosed after the era of antiretroviral treatment scale up: a call for re-invigorating the response in Iran. Int J STD AIDS 2013; 24: 926-930.

33. Komati S, Shaw PA, Stubbs N, et al. Tuberculosis risk factors and mortality for HIV infected persons receiving antiretroviral therapy in South Africa. AIDS 2010; 24: 1849-1855.

34. Carriquiry G, Fink V, Koethe JR, et al. Mortality and loss to follow-up among HIV-infected persons on long-term antiretroviral therapy in Latin America and the Caribbean. J Int AIDS Soc 2015; 18: 20016.

35. Ning S, Xue Z, Wei J, et al. HIV/AIDS related mortality in southern Shanxi province and its risk factors. Zhonghua Liu Xing Bing Xue Za Zhi 2015; 36: 245-249.

36. Farzadegan H, Hoover DR, Astemborski J, et al. Sex differences in HIV-1 viral load and progression to AIDS. Lancet 1998; 352: 15101514.

37. Brugal MT, Domingo-Salvany A, Puig R, et al. Evaluating the impact of methadone maintenance programmes on mortality due to overdose and aids in a cohort of heroin users in Spain. Addiction 2005; 100: 981-989.

38. Nakagawa F, Lodwick RK, Smith CJ, et al. Projected life expectancy of people with HIV according to timing of diagnosis. AIDS 2012; 26: 335-343.

39. May M, Gompels M, Delpech V, et al. Impact of late diagnosis and treatment on life expectancy in people with HIV-1: UK Collaborative HIV Cohort (UK CHIC) Study. BMJ 2011; 343: d6016.

40. Antiretroviral Therapy Cohort Collaboration, Zwahlen M, Harris $\mathrm{R}$, May M, et al. Mortality of HIV-infected patients starting potent antiretroviral therapy: comparison with the general population in nine industrialized countries. Int J Epidemiol 2009; 38: 1624-1633.

41. Razzaghi EM, Movaghar AR, Green TC, et al. Profiles of risk: a qualitative study of injecting drug users in Tehran, Iran. Harm Reduct J 2006; 3: 12. 